\title{
Climate change, population trends and groundwater in Africa
}

RICHARD C CARTER (1) and ALISON PARKER (2)

(1) Professor of International Water Development, Cranfield University, Cranfield, Bedford, MK43 0AL, UK. Email r.c.carter@cranfield.ac.uk (Corresponding Author) (2) Post-Doctoral Research Officer, Cranfield University.

\begin{abstract}
Global climate change is affecting Africa, as it is every other continent and region of the world. The absolute poverty of a large proportion of the continent's people renders them highly vulnerable to changes in climate. Mitigation of climate change is a global imperative. However numerous other changes continue apace, notably population growth, natural resource degradation, and ruralurban migration. Probably $50 \%$ or more of the continent's population rely on groundwater. This paper explores the relative impacts of changes in climate, demography and land use/cover on groundwater resources and demands. It concludes that the climate change impacts are likely to be significant, though uncertain in direction and magnitude, while the direct and indirect impacts of demographic change on both water resources and water demand are not only known with far greater certainty, but are also likely to be much larger. The combined effects of urban population growth, rising food demands and energy costs, and consequent demand for fresh water represent real cause for alarm, and these dwarf the likely impacts of climate change on groundwater resources, at least over the first half of the $21^{\text {st }}$ century.
\end{abstract}

Key words: climate change, population, groundwater, recharge, Africa

\section{INTRODUCTION}

It has been estimated (Carter and Bevan, 2008) that between one third and one half a billion people in sub-Saharan Africa use protected or unprotected groundwater for their daily water supply. Extending this estimate to the entire continent probably implies at least the upper end of that range, in other words that about $50 \%$ of Africa's nearly one billion population rely on shallow or deep groundwater.

The reality of climate change is almost undisputed now, and the findings of the fourth Intergovernmental Panel on Climate Change (IPCC, 2007) are stronger and more definite than ever before. The planet is warming, largely as a consequence of anthropogenic emissions of greenhouse gases. Rainfall and evapotranspiration rates will change too.

Changes in mean annual rainfall, as well as in its temporal and spatial distribution, would be expected to influence the water balance as a whole, and groundwater recharge in particular. The question of the likely impact of climate change on renewable groundwater resources is highly relevant, but under-researched (IPCC, 2007).

Feedbacks between climate change and population growth on one hand, and land use, land cover, hydrology and water resources on the other are complex, and the relationships involved likely to be highly non-linear.

Global climate change is probably the highest profile environmental issue at the present time, and its seriousness provides some justification for that prominence. However over the next few decades a more serious issue for less developed countries is the inexorable march of population growth. Just as climate change might be expected to affect future groundwater resources, so too an expanding population will place ever-increasing demands on water resources. Furthermore, population growth will indirectly impact on water resources, in ways that are not yet fully understood.

A number of questions arise in this context, when thinking about Africa's groundwater:

(a) What is likely to be the impact of global climate change on rainfall, other water balance components and groundwater recharge? 
(b) What will be the likely future increase in demand for groundwater due to population growth?

(c) How might demographic changes in turn affect the water balance, and groundwater recharge in particular?

(d) In terms of future research and action, where should our priorities lie?

In this paper an attempt is made to quantify the likely magnitudes of future change where that is possible, and to at least indicate in qualitative terms the likely direction and magnitude of other aspects. In order to explore the issues, first the global context of climate change is sketched; next the African rainfall context is described, with special reference to five countries spanning a range of climatic regions in Africa. After that, the likely trajectories of change in rainfall across Africa and the focus countries are summarised. The possible impacts of future rainfall change on groundwater recharge are discussed. Projections of demographic change in Africa as a whole and the focus countries are set out in detail. The possible impacts of demographic change on recharge are discussed. Finally some of the key linkages between climate change, population and groundwater are highlighted, and conclusions are drawn.

\section{GLOBAL AND AFRICAN TEMPERATURES}

Global mean temperatures are known to have been rising for at least the last hundred years, and there is evidence that the rate of warming is accelerating (IPCC, 2007). The global temperature rise in the $20^{\text {th }}$ century was about three-quarters of one degree, while the rate of rise in the second half of the century was nearly double that figure. Projections of global warming over the $21^{\text {st }}$ century depend on the models and scenarios used, but the best estimates by IPCC of temperature rise in the period 2080-2099 compared to 1980-1999 range from 1.8 to $4.0^{\circ} \mathrm{C}$. It is important to note that the rate of warming over land surfaces is higher than that for the globe as a whole.

To the extent that data are available, the corresponding observations and projections of warming for Africa are consistent with those for the globe. For Africa as a whole warming in the $20^{\text {th }}$ century has occurred at a rate of about $0.5^{\circ} \mathrm{C}$ per century, and the rate of warming increased in the last three decades of the century (Hulme et al., 2000). The $4^{\text {th }}$ IPCC projections for the A1B scenario (IPCC, 2007) for temperature present rather similar estimates of warming for all regions of Africa (Table 1 ), and varying only to a limited extent across seasons. In summary, annual mean temperatures are expected to rise by 3.2 to $3.6^{\circ} \mathrm{C}$ by the last 20 years of the century, compared to the corresponding period of the $20^{\text {th }}$ century.

Table 1 Temperature projections from a set of 21 global models in the multi-model dataset for the A1B scenario, for four regions of Africa (Figure 1), 2080-2099, compared to 1980-1999.

\begin{tabular}{llcc}
\hline Region & Bottom left & Top right & $\begin{array}{c}\text { Median annual temperature } \\
\text { response }{ }^{\circ} \mathrm{C}\end{array}$ \\
\hline West (WAF) & $12 \mathrm{~S}, 20 \mathrm{~W}$ & $22 \mathrm{~N}, 18 \mathrm{E}$ & 3.3 \\
East (EAF) & $12 \mathrm{~S}, 22 \mathrm{E}$ & $18 \mathrm{~N}, 52 \mathrm{E}$ & 3.2 \\
Southern (SAF) & $35 \mathrm{~S}, 10 \mathrm{E}$ & $12 \mathrm{~S}, 52 \mathrm{E}$ & 3.4 \\
Sahara (SAH) & $18 \mathrm{~N}, 20 \mathrm{E}$ & $30 \mathrm{~N}, 65 \mathrm{E}$ & 3.6
\end{tabular}




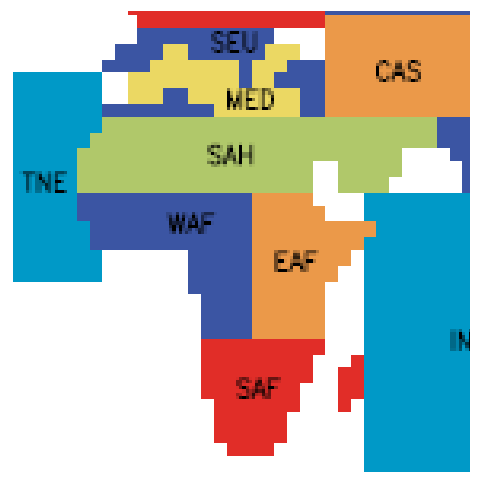

Figure 1 Regions of Africa used in the IPCC projections (IPCC, 2007)

\section{AFRICAN RAINFALL}

Rainfall in Africa is generally characterised by high variability between years, and in some regions (especially the Sahel) by multi-year runs of higher or lower than average rainfall. Within years, variations in starting date of the rains, end date of the rains, dry period duration, and extreme events are of great significance both for agriculture, which in the vast majority of African countries is predominantly rainfed, as well as for hydrology and water resources.

In this paper, use is made of the Africa Rainfall and Temperature Evaluation System (ARTES) ${ }^{1}$. This is a set of time series of spatially averaged rainfall and temperature data for every country in Africa. It has been composed by the World Bank from gridded ( 0.5 by 0.5 degree) datasets supplied by the US National Oceanic and Atmospheric Administration (NOAA).

To illustrate the temporal variability of rainfall at a number of timescales within Africa, example datasets have been extracted for five countries, selected to span east, west and southern Africa and reflect a range of rainfall regimes. Table 2 lists these countries, together with mean annual rainfall for the period 1948-2001, and the range of annual rainfalls within two standard deviations of the mean (assuming, as is usual and confirmed for these time series, that annual rainfall totals are normally distributed and that $95 \%$ of values fall within this range).

Table 2 Countries selected for analysis of past rainfall, and for future projections [Source ARTES data]

\begin{tabular}{lccc}
\hline Country & $\begin{array}{c}\text { MAR } \\
\text { 1948-2001, mm }\end{array}$ & $\begin{array}{c}\text { Rainfall range } \\
\text { (mean } \pm 2 \mathrm{SD}), \mathrm{mm}\end{array}$ & $\begin{array}{c}\text { 2SD as } \\
\text { \% of mean }\end{array}$ \\
\hline Uganda & 1240 & $1039-1441$ & 16 \\
Malawi & 1113 & $769-1458$ & 31 \\
Ethiopia & 916 & $751-1080$ & 18 \\
Sudan & 431 & $337-525$ & 22 \\
Niger & 215 & $119-311$ & 45 \\
\hline
\end{tabular}

MAR: Mean Annual Rainfall

SD: Standard Deviation

For the selected countries, it is apparent that about $95 \%$ of annual rainfalls typically lie in the range $\pm 16-45 \%$ around the mean. These results are shown graphically in Figure 2. Note that the spatial averaging involved in the use of gridded datasets would be expected to under-estimate the variability experienced at individual locations.

\footnotetext{
${ }^{1}$ For further information contact artes@worldbank.org
} 
The inter-annual and multi-year variability of rainfall is illustrated by Figure 3, which shows annual rainfalls for Niger for the period 1948-2001. In addition to the range of annual rainfall totals, the runs of relatively wet years (especially in the 1950s and 1960s) and dry years (in the early 1970s and mid-1980s) are evident.

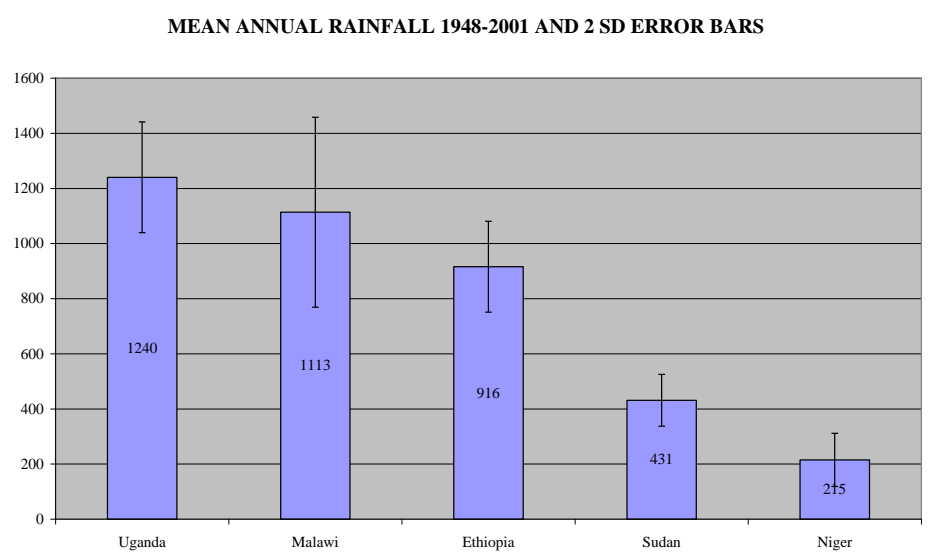

Figure 2 Mean annual rainfall \pm 2 SD for five selected countries in Africa (all values $\mathbf{m m}$ )

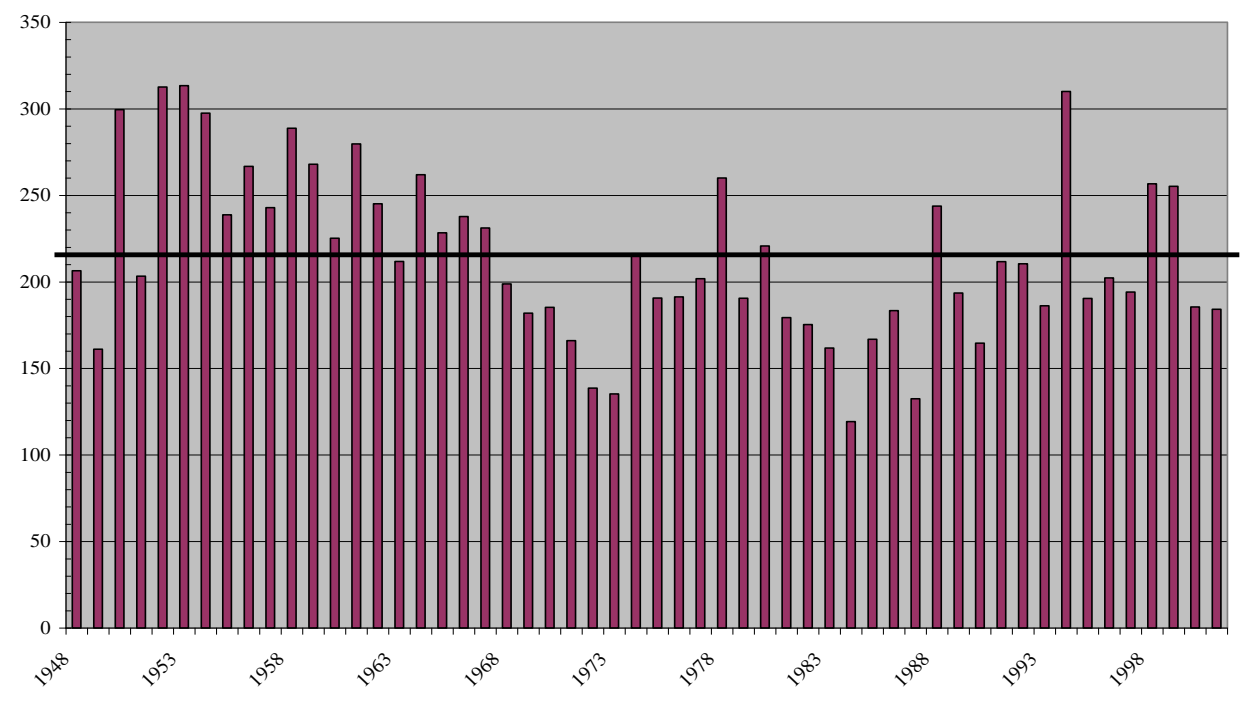

Figure 3 Annual rainfall 1948-2001, Niger, mm (solid line indicates MAR for the period)

The relationship between soil moisture content and rainfall varies with location, depending on the soil type, vegetation cover and evapotranspiration rate, hence to draw general conclusions is impossible. However to model recharge a knowledge of the soil water balance is required. The soil water balance is affected as much by within-year rainfall variation as by total seasonal or annual rainfall. Hydrologically effective rainfall (HER), in other words that which produces direct runoff and groundwater recharge, is usually characteristic of a particular season in which, for runoff, rainfall intensities are high, and for groundwater recharge, rainfall exceeds actual evapotranspiration and soil water content increases to the point at which potential recharge can occur. For example, in unimodal rainfall regimes (illustrated best by the Niger, Sudan and Malawi examples in this paper), HER is characteristic of the mid to end of the rains (August-September in Niger and Sudan; January-March in Malawi). For all five of the countries considered in this paper, the inter-annual variation in the rainfall for a particular month is, unsurprisingly, highest in percentage terms for the driest months, but greatest in absolute terms for the wettest months. This point is important when interpreting climate change projections expressed in terms of percentage change. Table 3 and Figure 4 illustrate the inter-annual variability of monthly rainfalls for the countries selected in this paper. 
Table 3 Mean (1948-2001) and variation of peak month rainfall for three countries with unimodal rainfall distributions.

\begin{tabular}{llcc}
\hline Country & $\begin{array}{l}\text { Peak rainfall } \\
\text { month }\end{array}$ & $\begin{array}{l}\text { Mean rainfall in } \\
\text { peak month, mm }\end{array}$ & $\begin{array}{l}\text { Range of peak month } \\
\text { rainfall }( \pm 2 \text { SDs }), \mathrm{mm}\end{array}$ \\
\hline Malawi & January & 239 & $117-361$ \\
Sudan & August & 103 & $59-147$ \\
Niger & August & 82 & $28-136$ \\
\hline
\end{tabular}
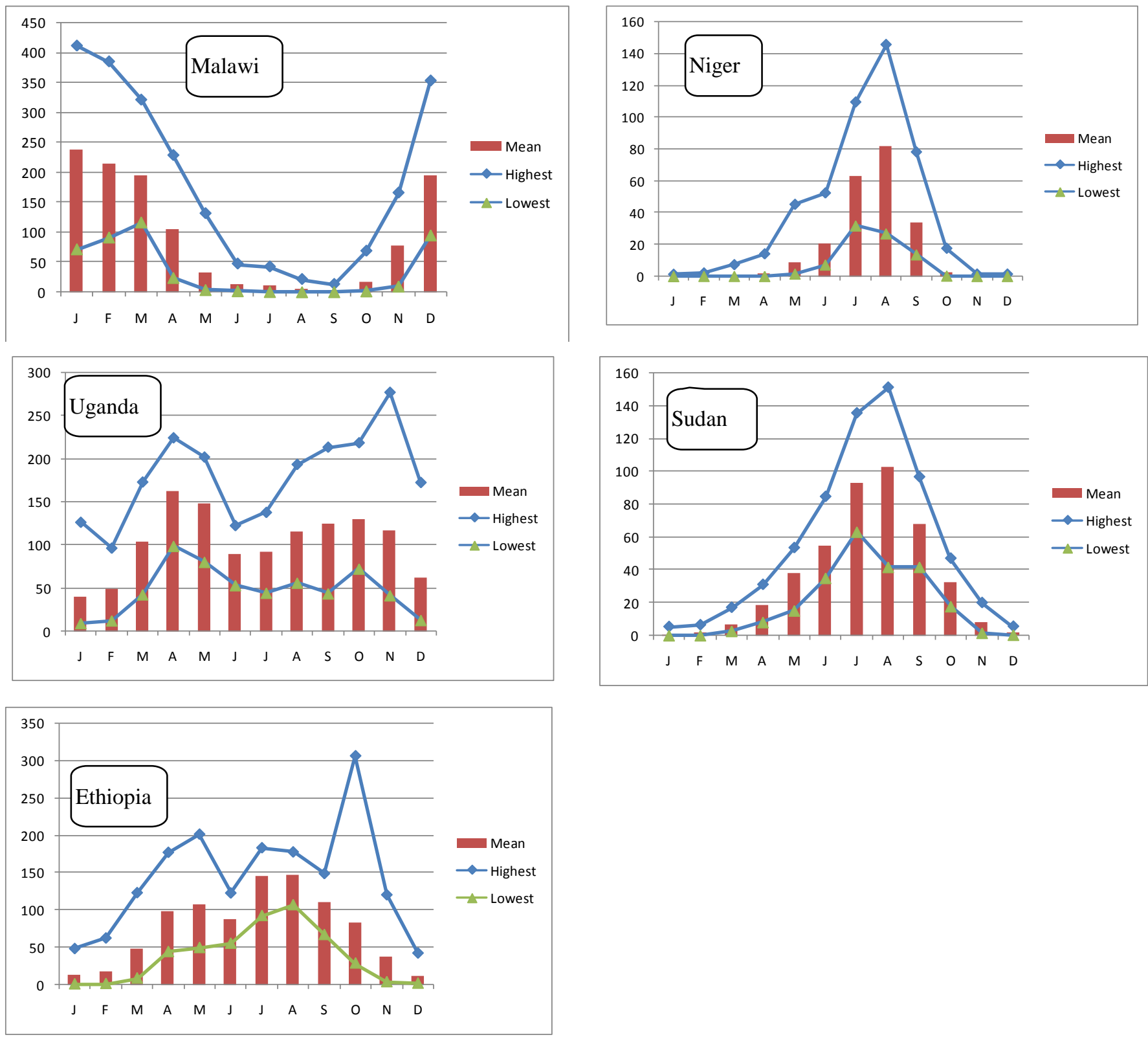

Figure 4 Mean and range of monthly rainfalls for five countries in Africa, 54 years, 19482001. Note different $y$-axis scales (all $\mathrm{mm}$ ), depending on country. Sources ARTES. 


\section{AFRICAN RAINFALL: PROJECTIONS OF CHANGE}

Projections of future rainfall change show much greater variability than temperature, and they vary by region and season (Table 4). Mean annual rainfall is likely to decrease in Mediterranean Africa, the northern Sahara, and southern Africa. Mean annual rainfall is likely to increase in east Africa. There is uncertainty about the southern Sahara, Sahel and Guinean coast. Note that the largest projected percentage changes tend to correspond to the driest (sometimes completely dry) periods.

Table 4 Summary of $4^{\text {th }}$ IPCC rainfall projections from the A1B scenario for four regions of Africa for 2080-2099 compared to end of $20^{\text {th }}$ century

\begin{tabular}{llc|llc}
\hline Region & Period & $\begin{array}{c}\text { Median } \% \\
\text { change }\end{array}$ & Region & Period & $\begin{array}{c}\text { Median \% } \\
\text { change }\end{array}$ \\
\hline \multirow{6}{*}{ WAF } & DJF & 6 & & DJF & 0 \\
& MAM & -3 & & MAM & 0 \\
& JJA & 2 & SAF & JJA & -23 \\
& SON & 1 & & SON & -13 \\
& Annual & 2 & & Annual & -4 \\
\hline \multirow{6}{*}{ EAF } & DJF & 13 & & DJF & -18 \\
& MAM & 6 & & MAM & -18 \\
& JJA & 4 & SAH & JJA & -4 \\
& SON & 7 & & SON & 6 \\
& Annual & 7 & & Annual & -6 \\
\hline
\end{tabular}

The four African regions used in the regional analyses of IPCC are large and climatically heterogeneous (IPCC, 2007). Higher resolution analysis is clearly needed, and despite the IPCC's comment that "... the extent to which current regional models can successfully downscale precipitation over Africa is unclear ...", there would appear to be little alternative to such downscaling if a more nuanced assessment of likely change is required.

As an indication of the possible trajectories of change in rainfall, data from the HadCM3 model, run with the A2 and B2 scenarios, is presented. HadCM3 is a coupled atmosphere-ocean general circulation model developed at the Hadley Centre in the UK (Gordon et al., 2000). The HadCM3 model outputs are presented for rectangular pixels surrounding grid points spaced 2.5 degrees latitude and 3.75 degrees longitude apart. These spacings translate to roughly $280 \mathrm{~km} \mathrm{x} 420 \mathrm{~km}$ at the equator. Figure 5 shows the grid points on a map of Africa. Table 5 summarises the projections for five selected grid points, one for each of the countries used in this paper.

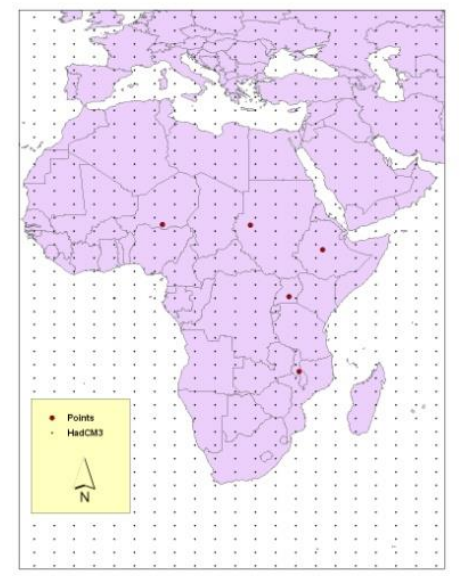

Figure 5 Grid points for HadCM3 model, Africa. Large dots show locations referred to in Table 5. 
Table 5 Rainfall baseline and projections for five 2.5 (lat) $\times 3.75$ (long) degree pixels in Africa [Note baseline refers to 1961-90 mean annual rainfall (MAR); projections are using HadCM3 model, scenarios A2 and B2 for 2050]

\begin{tabular}{lllll}
\hline $\begin{array}{l}\text { Pixel centre } \\
\text { (lat, long) }\end{array}$ & Approximate Location & $\begin{array}{l}\text { Baseline MAR, } \\
\mathrm{mm}\end{array}$ & $\begin{array}{l}\text { A2 MAR, mm } \\
\text { (\% change) }\end{array}$ & $\begin{array}{l}\text { B2 MAR, mm } \\
\text { (\% change) }\end{array}$ \\
\hline $0.00,33.75$ & Kampala, Uganda & 1108 & $1046(-5.6 \%)$ & $1038(-6.7 \%)$ \\
$-12.50,33.75$ & Salima, Malawi & 762 & $672(-11.9 \%)$ & $701(-9.1 \%)$ \\
$10.00,37.50$ & Addis Ababa, Ethiopia & 1344 & $1409(4.8 \%)$ & $1425(5.7 \%)$ \\
$12.50,26.25$ & Al Fashir, Sudan & 603 & $647(7.3 \%)$ & $649(7.2 \%)$ \\
$15.00,7.50$ & Zinder, Niger & 554 & $587(6.0 \%)$ & $562(1.4 \%)$ \\
\hline
\end{tabular}

In order to further corroborate these projections, the Tyndall Centre country dataset TYN CY 3.0 (Mitchell et al., 2004; Mitchell and Jones, 2005) was accessed, in order to examine rainfall projections to the year 2100 . This dataset contains country-by-country summaries of baseline and projected temperature, precipitation and other meteorological variables, obtained from four models, each run with four emissions scenarios. Among these are the HadCM3 model and the A2 and B2 scenarios. Table 6 sets out the results from this model and scenarios, while Figure 6 shows the results of all 16 runs (4 models $x 4$ scenarios) for one country (Uganda).

Table 6 HadCM3 results for five countries in Africa (from Mitchell et al., 2004)

[Note baseline is 1961-90; projections are for 2100]

\begin{tabular}{llll}
\hline Country & $\begin{array}{l}\text { Baseline } \\
\text { MAR, mm }\end{array}$ & $\begin{array}{l}\text { A2 MAR, mm } \\
\text { (\% change) }\end{array}$ & $\begin{array}{l}\text { B2 MAR, mm } \\
\text { (\% change) }\end{array}$ \\
\hline Uganda & 1180 & $1283(8.7 \%)$ & $1255(6.4 \%)$ \\
Malawi & 1182 & $1206(2.0 \%)$ & $1153(-2.5 \%)$ \\
Ethiopia & 847 & $957(13.0 \%)$ & $921(8.8 \%)$ \\
Sudan & 416 & $464(11.6 \%)$ & $448(7.8 \%)$ \\
Niger & 151 & $155(2.7 \%)$ & $170(12.5 \%)$ \\
\hline
\end{tabular}
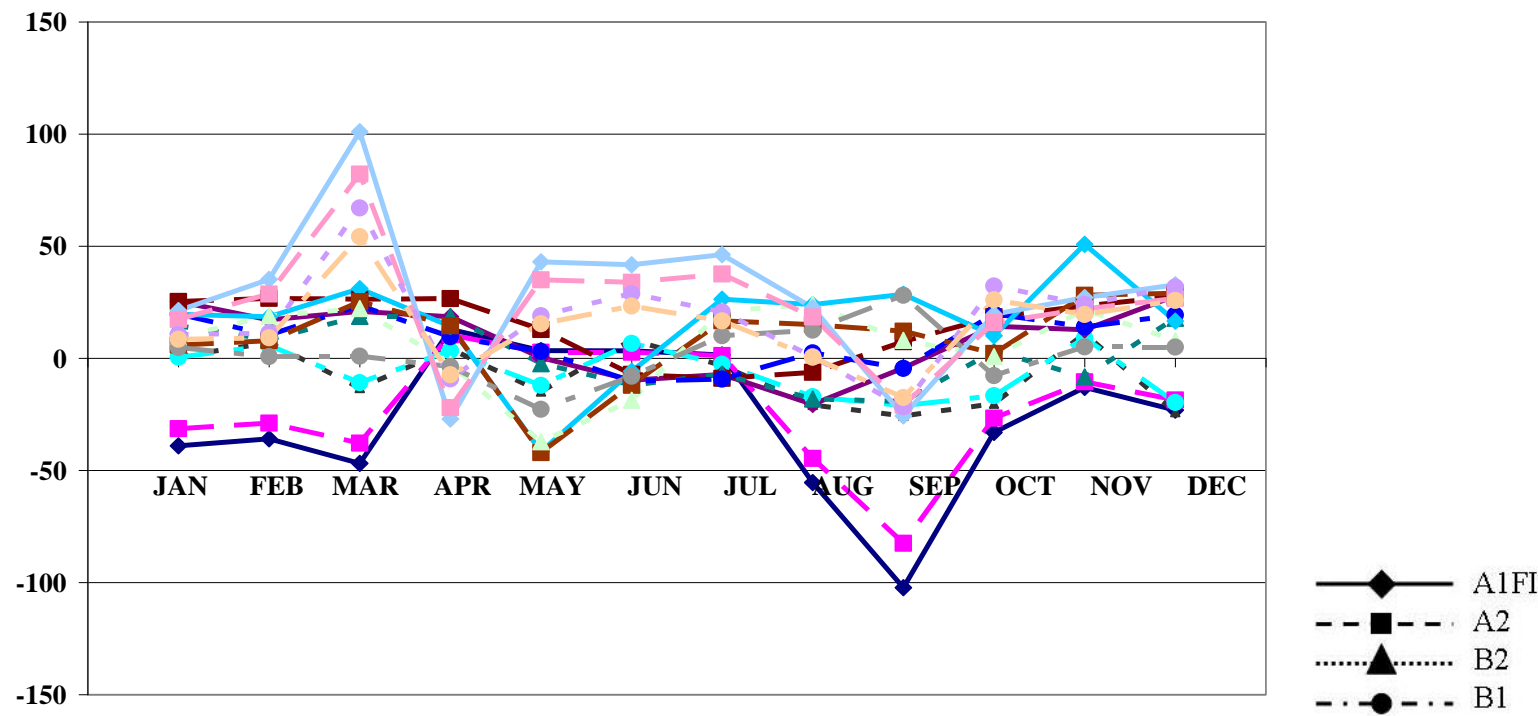

Figure 6 Projections of monthly rainfall change for Uganda (Mitchell et al., 2004)

[Note models used are CGCM2, CSIRO2, HadCM3 and PCM13, with SRES scenarios A1FI, A2, B2, B1; y-axis is projected change in mean monthly rainfall $(\mathrm{mm})$ by 2100 , compared to 1961-90] 
Comparison of Tables 5 and 6 highlights some apparent contradictions in the direction and magnitude of rainfall change. It should be noted that the tables refer to different geographical areas (Table 5 to a single $2.5^{\circ} \times 3.75^{\circ}$ pixel per country, Table 6 to entire countries) and different timescales (Table 5 to 2050, Table 6 to 2100). Nevertheless the differences draw attention to the uncertainties inherent in the projections. Figure 6 emphasises this further, demonstrating as it does the wide range of rainfall projections for one country by the end of the $21^{\text {st }}$ century.

An important point brought out in the fourth IPCC reports (IPCC, 2007) is that the frequency of extreme rainfall events is likely to increase, in Africa as in other regions.

\section{CLIMATE CHANGE IMPACTS ON FUTURE (GROUNDWATER) HYDROLOGY}

Changes in runoff and groundwater recharge which may result from alterations in rainfall and evapotranspiration in the future can be inferred from previous modelling investigations. It is already known (e.g. Rushton et al., 2006; Eilers et al., 2007) that annual runoff and recharge totals are more sensitive to short-term rainfall distribution than to the annual total rainfall, especially in semi-arid areas. An extended period of medium-intensity rainfall is more likely to lead to significant recharge than either a period of high-intensity rainfall (which will lead to increased runoff) or a period of low-intensity rainfall (most of which will evaporate). Two years with the same annual rainfall may give very different values of recharge, depending on the daily rainfall distribution.

Figure 7 shows the results of a daily soil water balance model (Eilers et al., 2007), run over a 37 year period (1961-97) to estimate potential groundwater recharge for a cropland location (Nguru) with a unimodal rainfall distribution in semi-arid north-east Nigeria. The annual recharge and annual rainfall have been extracted from the model data and output, and plotted in Figure 7. The figure clearly shows the variability of recharge even among years with similar rainfall totals. A lower limit of annual rainfall, below which recharge is unlikely, is also evident (in this case between 300 and $400 \mathrm{~mm}$ ). The variability of annual recharge is strongly influenced by the daily rainfall distribution.

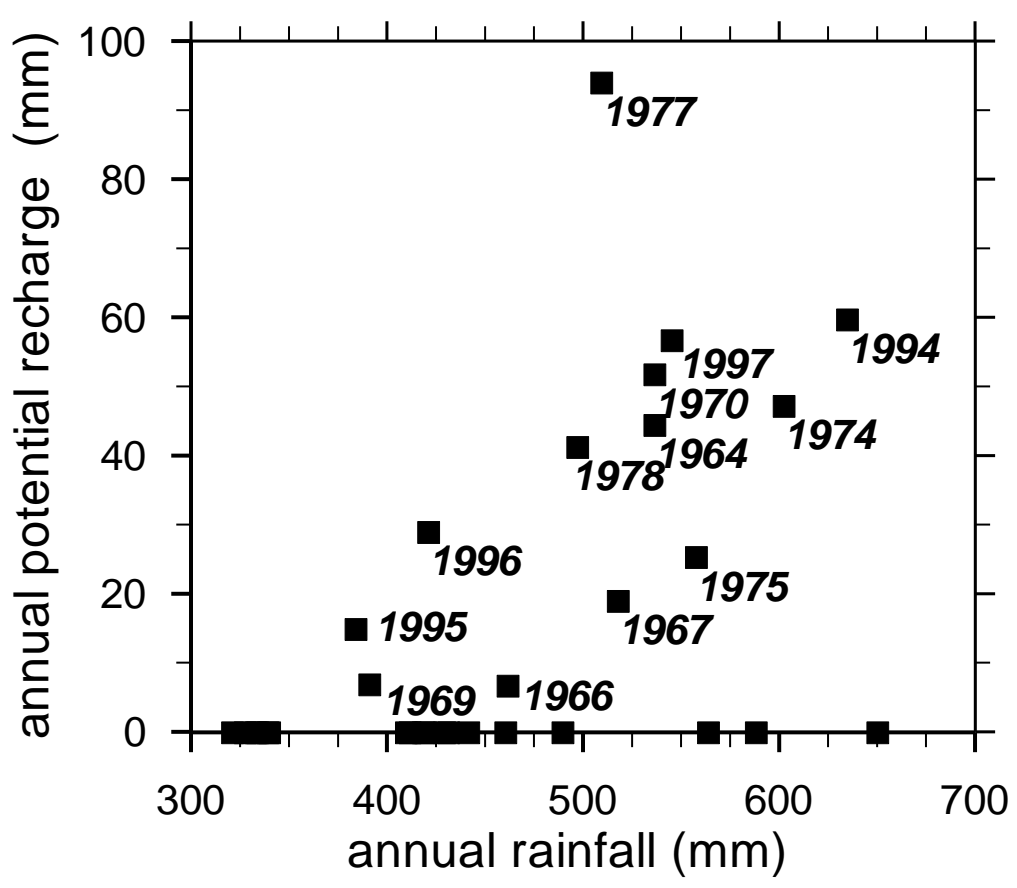

Figure 7 Modelled potential recharge and annual rainfall, Nguru, Nigeria (Eilers et al., 2007). 
It is well-known that any attempts to realistically model groundwater recharge using a soil water balance approach (arguably the only method suitable for exploration of future trends) require short period rainfall data (daily or better). This is especially so in drier climates. The present state of the art of climate change modelling cannot yet provide such rainfall datasets. In the absence of reliable knowledge of future daily rainfall time series, only indications of the direction of change can be made. Figure 8 shows the interactions between rainfall, runoff, infiltration, evapotranspiration and potential recharge in the simple single-layer water balance used to obtain the results in Figure 7 . In the computational model developed from Figure 8, runoff is a loss to the soil root zone, its magnitude depending on daily rainfall and soil properties. Evaporation and transpiration likewise represent losses from the root zone, and potential recharge (or deep drainage) only occurs once the soil water deficit in the root zone has been satisfied. Rushton and colleagues introduce the concept of near-surface storage to account for evaporation losses from rain falling on dry soil (Rushton et al., 2007). For a given soil type and vegetation cover, recharge estimated with models such as this is very sensitive to the daily pattern of rainfall, and less so to variations in potential evapotranspiration. If soil properties change, or alternative cropping or vegetation patterns are adopted, the situation becomes even more complex. The only way to model likely future recharge is to combine credible synthetic time series of daily rainfall with possible future changes in land use and soil physical properties.

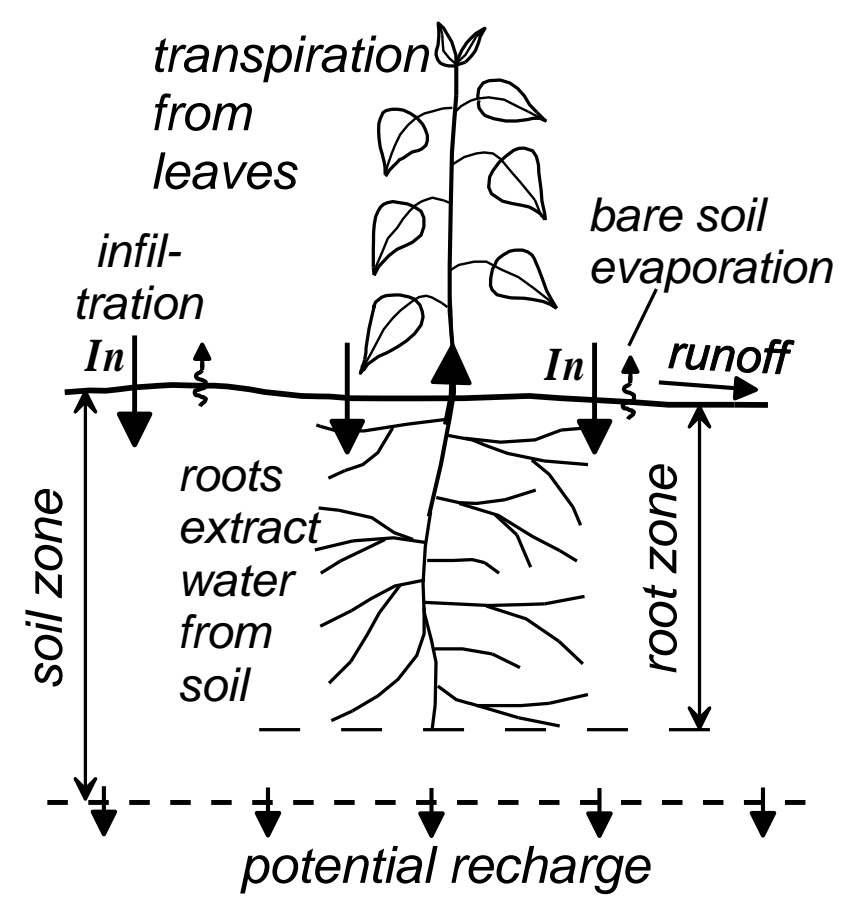

Figure 8 A simple single-layer conceptual model of groundwater recharge (Eilers et al., 2007)

\section{DEMOGRAPHIC CHANGE}

In contrast to knowledge of the direction and magnitude of rainfall and hydrological change, the prospects of demographic change in Africa in the $21^{\text {st }}$ century are known with considerable certainty. African population will grow (by about $154 \%$ between 2000 and 2050 under the UN medium variant, (119\% or 193\% under low and high variants respectively)) (UNFPA, 2000; UNFPA, 2008). The population will become increasingly urban (by $320 \%$ over the same period), and, as elsewhere, it will age (from a median age of 19 in 2005 to 28 in 2050) (UN, 2007). Two particular aspects of relevance to this paper are total and urban population numbers, shown here as Figure 9. 
It is well-established that demand for water grows over time as a consequence of both increasing population and changing water use patterns. Moreover, a significant aim of most water supply programmes is to increase per capita consumption, in order to enhance hygiene and health, and to secure food supply and other aspects of livelihoods. It would therefore be expected that overall demand for water will increase by at least $154 \%$ and more likely nearer to $200 \%$ in the first half of the $21^{\text {st }}$ century.

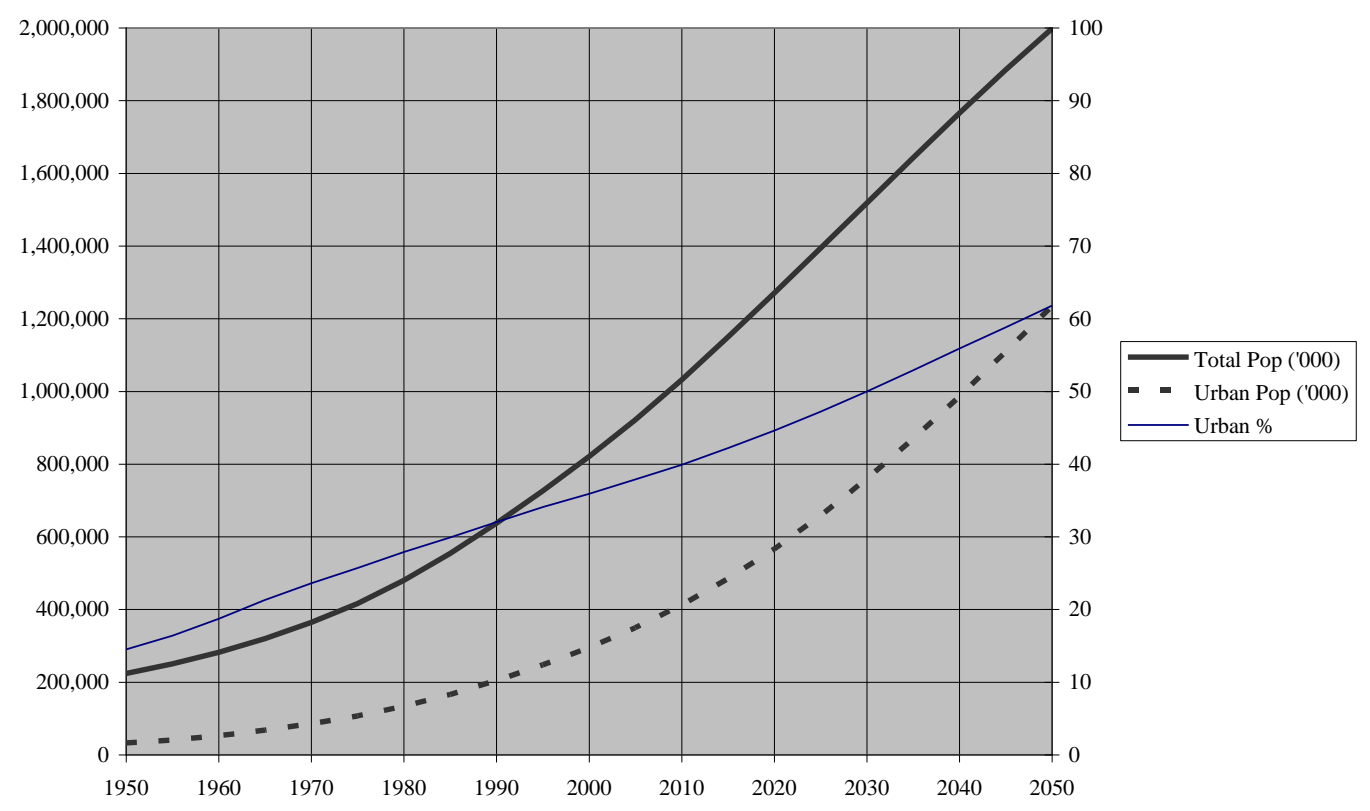

Figure 9 Total and urban population projections ('000) and urban \% (right-hand axis) for Africa (UN medium variant)

Africa's mean population density is projected to rise from 27 to 66 persons per $\mathrm{km}^{2}$ between 2000 and 2050. Assuming a per capita daily domestic water consumption of 20 litres, these figures translate to 0.2 and $0.5 \mathrm{~mm}$ annual water consumption respectively. Neither figure would give cause for concern if population were uniformly distributed and water demand were limited to 20 litres per capita per day. Less than $0.5 \mathrm{~mm}$ demand for water would impose little stress on an estimated continent-wide renewable annual freshwater resource of $3,930 \mathrm{~km}^{3}$ (equivalent to $131 \mathrm{~mm}$ over the $30 \mathrm{~m} \mathrm{~km}^{2}$ land mass - statistics from FAO, 2005).

However increased urbanisation, and increasing per capita consumption (both for domestic purposes and in intensified agriculture and industry) do give real cause for alarm. Nine African cities now figure in the top 100 ranked by population density, and the peri-urban areas of many others have similar or even higher densities. The City Mayors website includes Lagos (more than 18,000 persons $/ \mathrm{km}^{2}$ ), Cairo and Khartoum (between 5000 and $10,000 / \mathrm{km}^{2}$ ) and Cape Town, Durban, Accra, Lumumbashi, Pretoria and Johannesburg (each with densities between 2500 and 4000 per $\mathrm{km}^{2}$ ). Population densities 100 to nearly 700 times the continent-wide average impose very significant stresses on water resources, especially in drier parts of the continent. Similar observations apply to camps for internally displaced persons (IDPs) and refugees, where population densities of more than 20,000 persons per $\mathrm{km}^{2}$ are implied by the Sphere Humanitarian Disaster Response Standard of $45 \mathrm{~m}^{2}$ living area per person (The Sphere Project, 2004).

The Millennium Ecosystem Assessment projected that global water withdrawals could rise between 20 and 85\% between 2005 and 2050 (Millennium Ecosystem Assessment, 2005). However the rate of increase is likely to be higher in Africa as the per capita consumption is low currently but will 
increase as the population becomes wealthier. There is also an increasing demand across the continent to develop irrigation, and this is a particularly demanding use of water.

Rural population densities in Africa are also rising. In Uganda and Ethiopia for example, rural densities are projected to rise from 90 and 53 persons per $\mathrm{km}^{2}$ respectively in 2000, to 256 and 96 in 2050. When these figures are recalculated in terms of population per unit of cultivable land, the projections make uncomfortable reading (Table 7). The most extreme of the five countries considered in this paper, Ethiopia, is expected to be the tenth largest country in the world by population in 2050 . Already $83 \%$ of farming households occupy less than 2 ha, and $52 \%$ less than 1ha. Landlessness and poverty can only be expected to increase in the future as rural populations move upwards of 8 persons per ha of cultivable land.

Others have also emphasised the dominance of the effects of population growth over climate change on water stress (Vörösmarty et al., 2000). They formulated three scenarios for climate and population growth. The first scenario varied climate but fixed population and water withdrawals at 1985 levels. The second used the water demands of 2025, but used runoff and discharge based on contemporary climate. The third changed both climate and water demand. They calculated a ratio of water withdrawal to river discharge for all three scenarios at both a global and continental scales and found that the difference between the second and third scenarios was minimal, suggesting that increased population will put far more pressure on water resources than climate change.

Table 7 Years 2000 and 2050 populations per unit of cultivable land [Source, UN medium variant population projections combined with FAO AQUASTAT data]

\begin{tabular}{|c|c|c|c|c|c|c|c|}
\hline \multirow[t]{3}{*}{ Country } & \multicolumn{4}{|c|}{ Population (millions) } & \multirow{3}{*}{$\begin{array}{c}\text { Cultivable } \\
\text { land } \\
\left(\mathrm{km}^{2}\right)\end{array}$} & \multirow{2}{*}{\multicolumn{2}{|c|}{$\begin{array}{c}\text { Total population per ha o } \\
\text { cultivated land }\end{array}$}} \\
\hline & \multicolumn{2}{|c|}{2000} & \multicolumn{2}{|c|}{2050} & & & \\
\hline & Rural & Urban & Rural & Urban & & 2000 & 2050 \\
\hline Uganda & 19 & 3 & 62 & 31 & 167,600 & 1.3 & 5.5 \\
\hline Malawi & 9 & 2 & 16 & 15 & 53,000 & 2.1 & 6.0 \\
\hline Ethiopia & 53 & 10 & 106 & 77 & 132,000 & 4.7 & 13.9 \\
\hline Sudan & 19 & 11 & 19 & 54 & $1,085,700$ & 0.3 & 0.7 \\
\hline Niger & 8 & 2 & 33 & 20 & 380,000 & 0.3 & 1.4 \\
\hline
\end{tabular}

The demographic trends just outlined make three outcomes almost certain:

- Increased urban populations and high population densities will increase domestic and industrial water demands, putting enormous strain on the water resources supplying towns and cities. Urban water demands are likely to increase by at least a factor of 4 by 2050 (compared to 2000). The demands of increasing population are likely to outstrip any problems caused by climate change.

- Increased urban populations need feeding, and this in turn will require significant food production increases in both rural and peri-urban areas; by 2050 the urban population of Africa will have increased by nearly $950 \mathrm{~m}$ compared to 2000 - a figure rather close to the present day total population of the continent.

- Increasing pressure on land in rural areas will of necessity accelerate the development of irrigated production, so stressing water resources there too. By 2050 the absolute growth in rural population compared to 2000 is projected to be nearly $240 \mathrm{~m}$, a $45 \%$ increase. Rural and urban food security will only be achieved in a continent having such time-variant rainfall, through a re-emphasis on irrigation and water management. 


\section{IMPACTS OF DEMOGRAPHIC CHANGE ON GROUNDWATER RECHARGE}

Groundwater recharge is influenced by climate (rainfall and evapotranspiration), soil type (infiltrability and water holding capacity), and land cover (natural vegetation or crops). In any given environment any one of these attributes may act as the limiting factor. All three can change. Climate change is the focus of this paper, but soil properties and (especially) land use can and do change over time, sometimes very significantly.

Recharge may be diffuse (or direct) resulting from excess precipitation over and above that which the soil can retain within the root zone of vegetation. The surplus moves downward as potential recharge, ultimately joining the water table as actual recharge. Alternatively it may be localised (or indirect), resulting from concentration of runoff, followed by infiltration and deep percolation.

In Africa's semi-arid and arid climates, where groundwater resources tend to be most stressed, recharge occurs by both diffuse and localised mechanisms, the relative magnitude of each depending on rainfall distribution and soil type. In this context, a number of papers describing recharge studies in various dry regions of Africa extending back to the 1950s (Carter and Barber, 1958; Jones, 1960; Leduc et al., 2001; Seguis et al., 2004; Scanlon et al., 2006) document significant increases in groundwater recharge consequent upon land use change, specifically the clearing of deep-rooted natural vegetation, and its replacement by annual (short-rooted, short duration) crops. Despite severe and extended droughts at various times in the second half of the $20^{\text {th }}$ century, land use changes of this type have been shown to increase recharge rates by an order of magnitude and bring about water table rises of up to $2.3 \mathrm{~m} / \mathrm{a}$.

Few attempts have been made to project changes in groundwater recharge that may come about as a consequence of climate change. One recently published attempt however appears rather alarmist (Cavé et al., 2003). These authors present a scattergram of recharge estimations against annual rainfall for three countries in southern Africa, and conclude that a reduction in MAR from 500mm to $400 \mathrm{~mm}$ could result in an $80 \%$ reduction in annual recharge. However this simplistic analysis fails to take any account of either the wide scatter within the presented data, or the reasons behind that scatter, which are almost certainly to do with inter-annual daily rainfall distribution, and spatial variability of soil properties and land cover. Other authors working in a humid region of central Uganda also explored the relationship between annual recharge, modelled by a soil moisture balance, and annual precipitation, finding only a weak correlation between these values (Taylor and Howard, 1996). However the correlation between modelled recharge and the number of heavy rain events (>10mm/day) was found to be stronger.

In the dry regions at least, the consensus would appear to be that land use and land management can be at least as important as climatic factors in determining groundwater recharge: “. .. sensitivity of recharge to land use/land cover changes suggests that recharge may be controlled through management of land use" (Scanlon et al., 2006)

\section{CONCLUSIONS}

The analyses in this paper lead to a number of conclusions, each having enough certainty to point the way ahead:

(a) Global climate change will affect Africa, as elsewhere, with projected warming of $3-4^{\circ} \mathrm{C}$ by the end of the $21^{\text {st }}$ century.

(b) The impact on African rainfall is likely to vary considerably from place to place (the GCM models and scenarios are not consistent in either the direction or magnitude of such change for particular locations). However the impact on mean annual rainfall may be as much as $\pm 10-20 \%$, superimposed on a background present-day inter-annual variability of at least twice that figure. The frequency of extreme events may increase.

(c) The impact of rainfall change on groundwater recharge is unknown, but it depends primarily on short-period (daily) rainfall distribution within the rainy season, and land-use/land cover. The 
first is not known with certainty, but past trends in land use (clearance of natural vegetation and intensification of agriculture) are likely to continue and accelerate through the present century.

(d) Africa's population is increasing rapidly, with a four-fold increase in urban population and an increase in rural population of $45 \%$ projected by 2050 (compared to 2000). This will place massively increased and concentrated demands on water resources, both for domestic and industrial use in the towns and cities, and for agricultural use in the rural areas and urban fringes. This increase in demand is likely to dwarf any likely reductions in renewable fresh water resources consequent upon climate change.

(e) The consequences of population growth and urbanisation will be that the first half of the $21^{\text {st }}$ century will see a significant growth in water and food-related poverty and hunger. When combined with rising energy costs, increased cultivation of biofuels and rising food prices, this should be the cause of alarm, much more so than the (unknown, and probably smaller) direct impacts of climate change.

(f) Research into the likely future impact of climate change on groundwater recharge is needed, but an equal priority should be placed on:

(i) monitoring of groundwater levels over the long term to establish actual change, as a reality check on models and projections;

(ii) developing sound conceptual and quantified models that explicitly link climate variability and change, population growth and water demand, land use and land cover change, hydrology and water resources;

(iii)quantifying likely future urban and agricultural demands on fresh water resources, and on groundwater in particular;

(iv)finding environmentally and functionally sustainable solutions for the present and nearfuture water emergency represented by the massively expanding need for domestic, industrial and (especially) agricultural water in Africa.

\section{ACKNOWLEDGMENTS}

We would like to acknowledge Dr Richard Taylor of University College for initiating and planning the conference for which this paper is a contribution. Financial support for attendance at the conference was provided by the UK Department for International Development. The HadCM3 2050 rainfall projections were extracted by my colleague Carlos Berna Esteban. Helpful discussions with a number of colleagues, especially Dr Jerry Knox, resulted in improvements to the paper. Many thanks to all of these for their valuable assistance and contributions.

\section{REFERENCES}

Carter, R. C. \& Bevan, J. E. (2008) Groundwater development for poverty alleviation in subSaharan Africa. In Adelana, S and MacDonald A M (Eds) Applied Groundwater Studies in Africa. Selected Papers on hydrogeology, 13. International Association of Hydrogeologists. CRC Press.

Carter, J. D. \& W. Barber (1958) The Rise in the Water Table in Parts of Potiskum Division, Bornu Province. Records of the Geological Survey of Nigeria 1956. Federation of Nigeria/Ministry of Mines and Power.

Cavé, L., Beekman, H. E., \& Weaver, J. (2003) Impact of climate change on groundwater recharge estimation. In Groundwater recharge estimation in southern Africa. (ed. by Y Xu and H.E Beekman) (2003) UNESCO IHP Series No 64.

Dinar, A., Hassan, R., Mendelsohn, R., \& Benhin, J. (2008) Climate change and agriculture in Africa. Earthscan, UK and USA. ISBN 13-978-1-84407-547-8. 
Eilers, V. H. M., Carter R. C. \& Rushton, K. R. (2007) A single layer soil water balance model for estimating deep drainage (potential recharge): An application to cropped land in semi-arid Northeast Nigeria. Geoderma. 140, 119-131.

FAO (2005) Irrigation in Africa in figures: AQUASTAT Survey 2005, FAO Water Report. 29. http://www.fao.org/nr/water/aquastat/regions/africa/index.stm

Gordon, C.; Cooper, C., Senior, C.A., Banks, H., Gregory, J.M., Johns, T.C., Mitchell, J.F.B., \& Wood, R.A. (2000). The simulation of SST, sea ice extents and ocean heat transports in a version of the Hadley Centre coupled model without flux adjustments. Climate Dynamics. 16: 147-168.

Hulme, M., Doherty, R., Ngara, T., New, M., \& Lister, D. (2000) African Climate Change: 19002100. Climate Research. 17, 145-168.

IPCC (2000) IPCC Special Report Emissions Scenarios: Summary for Policymakers. ISBN 929169-113-5.

IPCC (2007) Climate Change 2007: the Physical Science Basis. Contribution of Working Group I to the Fourth Assessment Report of the Intergovernmental Panel on Climate Change. Cambridge University Press. ISBN 978-0-521-70596-7. Climate Change 2007: Impacts, Adaptation and Vulnerability. Contribution of Working Group II to the Fourth Assessment Report of the Intergovernmental Panel on Climate Change. Cambridge University Press. ISBN 978-0-52170597-4.

Jones D. G. (1960) The Rise in the Water Table in Parts of Daura and Katsina Emirates, Katsina Province. Records of the Geological Survey of Nigeria 1957. Federation of Nigeria/Ministry of Mines and Power.

Leduc, C., Favreau, G., and Schroeter, P. (2001) Long-term rise in a Sahelian water table: the Continental Terminal in south-west Niger. Journal of Hydrology. 243, 43-54.

Millennium Ecosystem Assessment (2005) Millennium Ecosystem Assessment Synthesis report Mitchell, T. D., Carter, T. T., Jones, P. D., Hulme, M. \& New, M. (2004) A comprehensive set of high resolution grids of monthly climate for Europe and the globe: the observed record (1901-2000) and 16 scenarios (2001-2100). Tyndall Centre for Climate Change Research, Working Paper 55.

Mitchell,T. D. \& Jones, P.D. (2005) An improved method of constructing a database of monthly climate observations and associated high-resolution grids. International Journal of Climatology. 25 , 693-712.

O’Neill, B. C., MacKellar, F. L., \& Lutz, W (2001) Population and climate change. Cambridge University Press. ISBN 13-978-0-521-66242-0.

Rushton K. R., Eilers V. H. M. \& Carter R. C. (2006) Improved soil moisture balance methodology for recharge estimation. Journal of Hydrology. 318, 379-399.

Scanlon, B, Keese, K. E., Flint, A. L., Flint, L. E., Gaye, C. B., Edmunds, W. M., \& Simmers, I (2006) Global synthesis of groundwater recharge in semiarid and arid regions. Hydrological Processes. 20, 3335-3370.

Seguis, L., Cappelaere, B., Milesi, G., Peugeot, C., Massuel, S. \& Favreau, G. (2004) Simulate impacts of climate change and land clearing on runoff from a small Sahelian catchment. Hydrological Processes. 18, 3401-3413.

Stern, N (2007) The economics of climate change: the Stern Review. Cambridge University Press. ISBN 13-978-0-521-70080-1.

Taylor, R. G., \& Howard, K. W. F. (1996) Groundwater recharge in the Victoria Nile basin of East Africa: support for the soil moisture balance approach using stable isotope tracers and flow modelling. Journal of Hydrology, 180, 31-53 
The Sphere Project (2004) Humanitarian Charter and Minimum Standards in Disaster Response, The Sphere Standard, Geneva, ISBN 92-9139-097-6

Thornton, P. K., Jones, P. G., Owiyo, T., Kruska, R..L., Herrero, M., Kristjanson, P., Notenbaert, A., Bekele, N. \& Omolo, A. (2006) Mapping climate vulnerability and poverty in Africa. Report to the Department for International Development. ILRI, PO Box 30709, Nairobi 00100, Kenya.

UN (2007) World population prospects: the 2006 Revision, Highlights. Population Division of the Department of Economic and Social Affairs of the United Nations Secretariat. ESA/P/WP.202. Database on population at http://esa.un.org/unpp/index.asp?panel=2. Database on urbanisation trends at http://esa.un.org/unup.

UNDP (2007) Human Development Report 2007/2008 Fighting climate change: human solidarity in a divided world. Palgrave Macmillan. ISBN 978-0-230-54704-9.

UNFPA (2000) The state of world population. Lives together, worlds apart: men and women in a time of change, United Nations Population Fund. ISBN 0-89714-582-8.

UNFPA (2008) State of world population 2008. Reaching common ground: culture, gender and human rights. United Nations Population Fund. ISBN 978-0-89714-889-4.

Vörösmarty, C. J., Green, P., Salisbury, J., Lammers, R. B. (2000), Global water resources: Vulnerability from Climate Change and Population Growth, Science 289, 284-288. 